\title{
Dual Band Gap Coupled Antenna Design with DGS for Wireless Communications
}

\author{
Abhishek Kandwal*, Rakesh Sharma and Sunil Kumar Khah \\ Electromagnetic Analysis Lab, Department of Physics, Jaypee University of Information Technology, \\ Waknaghat, Distt. Solan-173215, H.P (India) \\ *corresponding author, E-mail: kandwal_abhishekerediffmail.com
}

\begin{abstract}
A novel gap coupled dual band multiple ring antenna with a defected ground structure (DGS) has been successfully implemented. A different technique is used in this communication where both gap coupling and defected ground are applied to obtain better results for wireless applications. The designed antenna operates in two different frequency bands. The antenna shows a wideband in C-band and also resonates in the $\mathrm{X}$-band. The main parameters like return loss, impedance bandwidth, radiation pattern and gain are presented and discussed. The gain is increased and the side lobe level is considerably reduced to a good extent. Designed antenna is tested and the results show that the simulation and experimental results are in good agreement with each other.
\end{abstract}

\section{Keywords}

Microstrip, gap coupled, wireless, defected ground, dual, wideband

\section{Introduction}

Microstrip or printed antennas are being considered and used in a variety of communication systems due their many attractive features, including low profile and ease of integration with microwave and photonic devices. However, despite these advantages over conventionally designed antennas there are several shorting comings of the printed antenna such as its relatively small bandwidth, excitation of surface waves, poor polarization purity, spurious feed radiation, low power, tolerance problems which limits their more widespread applications, etc [1]. Bandwidth of microstrip antenna has been increased by various methods such as, using thick low dielectric constant substrate, planar gap-coupled multiple resonators, stacking the patches over each other, etc . However, using a thicker substrate causes generation of spurious radiation and there are some practical problems in decreasing the dielectric constant. The spurious radiation degrades the antenna parameters [2-3]. Now days defected ground microstrip patch antennas have been rapidly developed for multi-band and broadband in wideband communication systems [4-6]. The use of microstrip defected ground geometry antennas in electromagnetic radiations has been a recent topic of interest in the world. A defected ground antenna can be designed to receive and transmit over a wide range of frequencies. In this defected ground structure or DGS technique, the ground plane metal of a microstrip (or strip-line, or coplanar waveguide) circuit is intentionally modified to enhance performance [7-10].

Microstrip patch defected ground antennas have been rapidly developed for multi-band and broad band in high data rate systems known as wideband communication systems. The use of microstrip defected geometry antennas in electromagnetic radiations has been a recent topic of interest in the world [11-14].

In this communication, a simple structure of printed gap coupled multiple ring defected ground antenna working in two different frequency bands has been investigated both by using a simulation software and experimentally. A significant matched bandwidth is obtained. Simulation and experimental results show that this type of antenna can achieve better performance and wide matched impedance bandwidth.

\section{Theory}

The gap coupled multiple ring defected ground microstrip patch antenna has been credited for its inherently wide impedance bandwidth. Impedance bandwidth can be efficiently increased to a good extent by using gap coupling method [15]. Defected ground structures (DGS) have been developed to improve characteristics of many microwave devices. Because of its properties, these structures have found many applications in microwave circuits such as 
filters, power amplifiers, dividers, microwave oscillator and harmonic control in microstrip antennas [16-18]. Defected ground structures, either in a single configuration or periodic form that is frequently referred to as a photonic band gap show slow-wave effects leading to considerable size realization. Recently a defected ground structure (DGS) have been introduced, DGS is realized by etching off a simple shape defected from the ground plane, depending on the shape and dimensions of the defect, the shielded current distribution in the ground plane is disturbed resulting a controlled excitation and propagation of the electromagnetic waves through the substrate layer. The dimension of the DGS is optimized for the band gap at the resonant frequency of the antenna by trial and error approach [19-21]. Dual frequency operation of antennas has become a necessity for many applications in wireless communication systems such as GPS, GSM services operating at two different frequency bands and services of PCS and IMT-2000 applications. Although there are various techniques to achieve dual-band operation from various types of microstrip antennas, there is no efficient design tool that has been incorporated with a suitable optimization algorithm [22-24].

In the present communication, dual band characteristics of the gap coupled antenna design without defected ground and with defected ground plane are presented. The measurements such as return loss, input impedance, and bandwidth are measured and calculated. The radiation characteristics such as antenna gain, back radiation and side lobe level are presented and discussed. The peak antenna gain for the central resonant frequency is increased and the corresponding back radiation and the side lobe level are reduced.

\section{Antenna design and parameters}

The proposed structure of printed gap coupled multiple ring antenna is shown in figure (1). Antenna design printed on a substrate has thickness or height ' $h$ '. The relative permittivity of the substrate used is ' $\varepsilon_{\mathrm{r}}$ '. The substrate plane is a square in shape and dimensioned as $\mathrm{L}_{\mathrm{s}} \times \mathrm{L}_{\mathrm{s}}$. The dimensions of the ground plane that is the metal strip of the designed antenna is represented as $\mathrm{L}_{\mathrm{g}} \times \mathrm{L}_{\mathrm{g}}$. The geometry of the structure consists of two rings with inner and outer radii. The inner and outer radii of the first ring are ' $a$ ' and ' $b$ '. The inner and outer radii of the second ring are 'c' and ' $d$ '. The microstrip ring antenna has inner and outer ring with the condition a $<\mathrm{b}<\mathrm{c}<\mathrm{d}$. The inner and outer radii of the first ring are $a=5 \mathrm{~mm}$ and $b=15 \mathrm{~mm}$. The inner and outer radii of the second ring are $\mathrm{c}=30 \mathrm{~mm}$ and $\mathrm{d}=60 \mathrm{~mm}$. The antenna is fed coaxially at the first ring at a distance of $9 \mathrm{~mm}$ from the center to achieve $50 \Omega$ characteristic impedance. The antenna has dimensions of $124 \mathrm{~mm} \times 124 \mathrm{~mm}$. The ground plane is only under part of the feed and the rest of the ground plane is completely removed. The width of the ground plane is $30 \mathrm{~mm}$ and has dimensions 30 $\mathrm{mm} \times 124 \mathrm{~mm}$. The prototype of the antenna designed is shown in the figure (2). The proposed defected ground multiple ring antenna design is printed over a glass epoxy resin substrate with permittivity of $\varepsilon=4.4$ and height $\mathrm{h}=1.59 \mathrm{~mm}$. The geometry of the structure with ground plane covering whole of the substrate that is when ground plane is not defected, is same as that of the structure with defected ground plane. All the other parameters used for the antenna study remain unchanged.

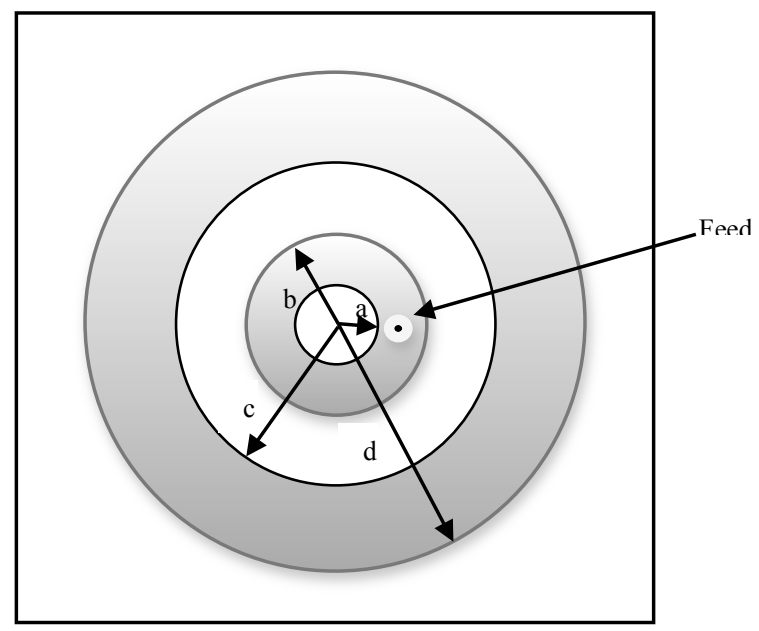

(a)

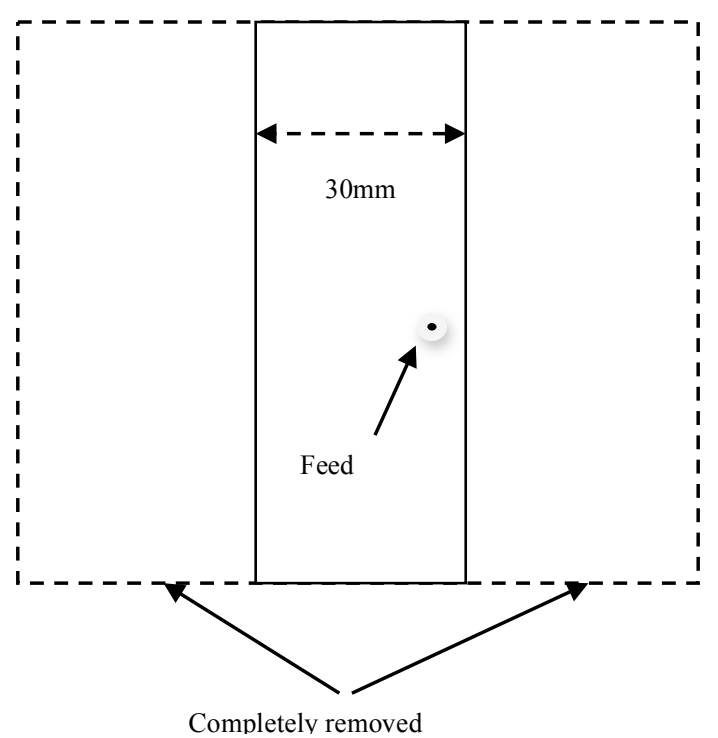

(b) 


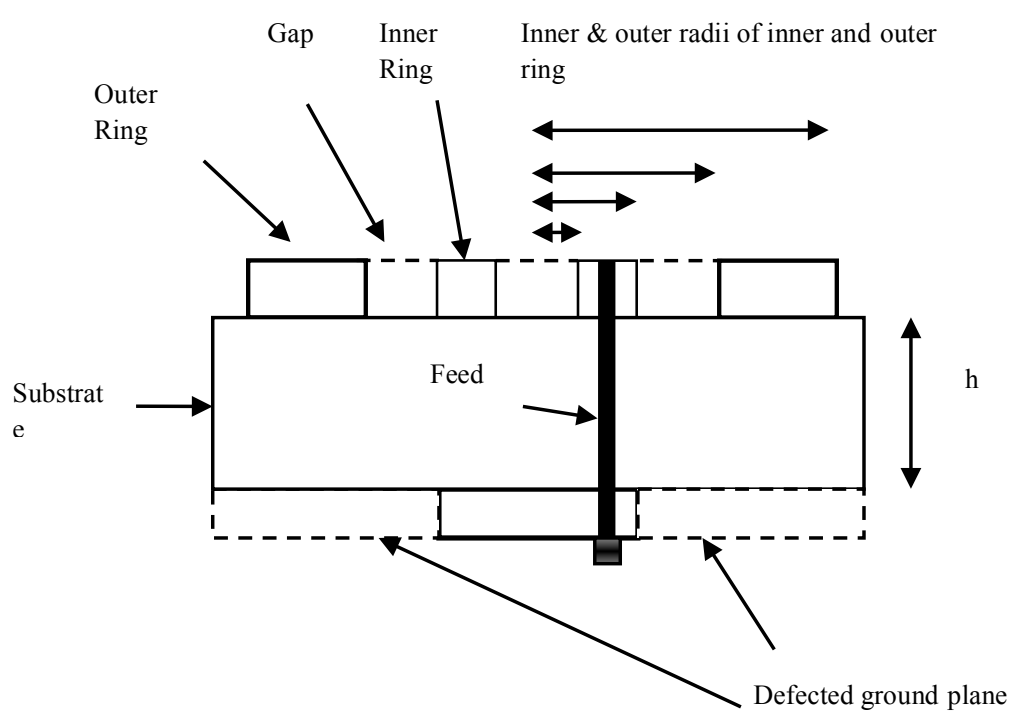

(c)

Figure 1. Geometry of Multiple ring gap coupled DGS microstrip antenna design

(a) top view (b) bottom view (c) side view.

In this study, the software CST studio suite is used to simulate the parameters such as return loss, impedance bandwidth and gain. Simulation software CST studio suite is based on the finite integration technique method has been widely accepted in the computation of electromagnetic field because of its good calculating precision. R\&S ZVL Network Analyzer is used to measure parameters such as S11 that is return loss and the impedance bandwidth. Figure (1) shows the top and bottom views of the antenna under study respectively. The experimental antenna design is also shown in figure (2).

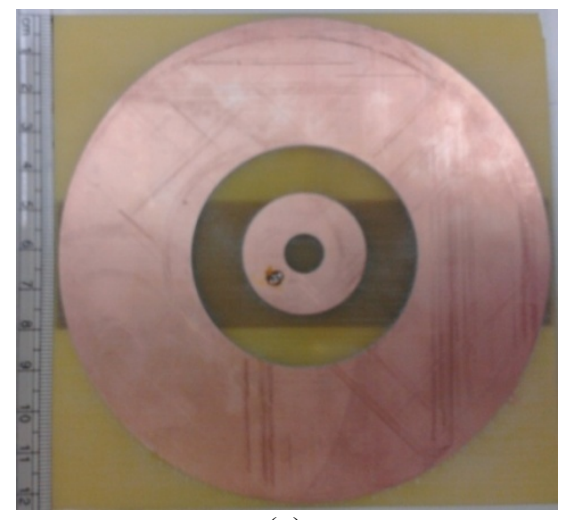

(a)

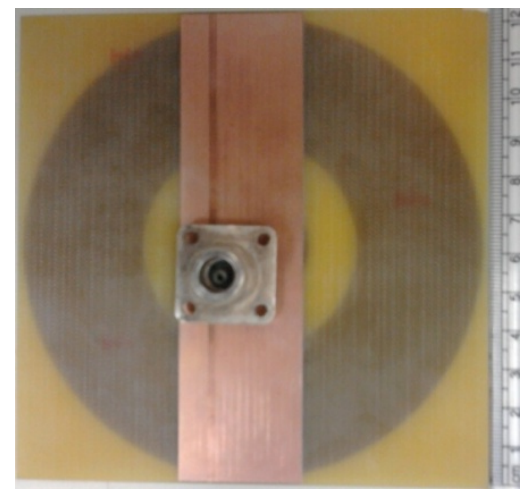

(b)

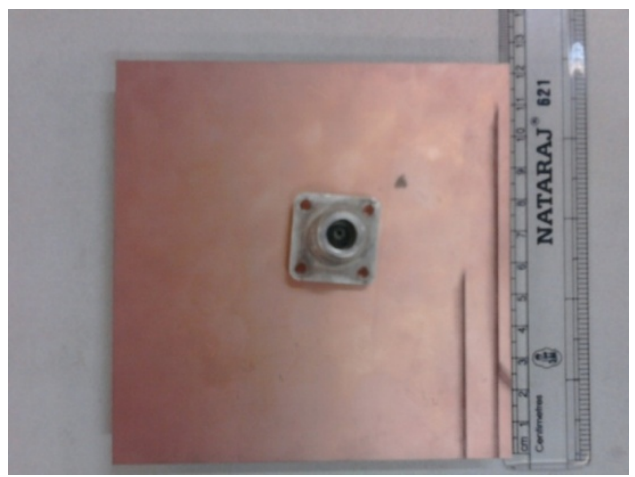

(c)

Figure 2. Multiple ring gap coupled DGS microstrip antenna design for experiment(a) top view (b) bottom view (with defect) (c) bottom view (without defect).

\section{Results and discussion}

The results for both the cases, that is antenna structure without defected ground plane and structure with defected ground plane, are measured and discussed. The radiation pattern, antenna gain, side lobe level, back radiation are thus presented for both antenna structures.

\subsection{Return loss and Impedance measurements}

When the ground plane is not defected, that is when it covers whole of the substrate; the antenna resonates only in C-band at frequency $6.2 \mathrm{GHz}$ showing an impedance bandwidth of approximately $4 \%$. The simulated and measured values of return loss are shown in figure (3). The input impedance for both simulated and measured is shown in figure (4). But when the defect in the ground plane is introduced then the antenna resonates in two frequencies. The simulated and measured values of return loss are shown in figure (5). Both experimental and simulated results are in good agreement with an error of less 
than $2 \%$. From figure (5), the simulation results show that the designed antenna resonates at two different frequency bands. The simulation results have good impedance matching of $-29.4 \mathrm{~dB}$ and -15.8 $\mathrm{dB}$ at frequencies $4.75 \mathrm{GHz}$ and $10.2 \mathrm{GHz}$ respectively. Also, the experimental results have good impedance matching $-27.4 \mathrm{~dB}$ and $-17.8 \mathrm{~dB}$ at frequencies $4.85 \mathrm{GHz}$ and $10.4 \mathrm{GHz}$ respectively. From the graphs; the percentage bandwidth obtained for simulated and experimental results in the frequency range between $4 \mathrm{GHz}$ to $6 \mathrm{GHz}$ is $12.5 \%$ and $12.3 \%$ respectively.

The figures show that, this antenna is wideband and also applied in two different bands that is C-band and $\mathrm{X}$-band since in these frequencies the $S 11<-10 \mathrm{~dB}$. A good return loss of $-32 \mathrm{~dB}$ is obtained as shown in the graph. Therefore the results verify that by introducing defect in the ground plane, a considerable increase in the impedance bandwidth is obtained. The increase in the bandwidth of the antenna is about $8 \%$ to $9 \%$. Also the antenna resonates in two frequency bands and thus showing the dual band characteristics.

The input impedance for both the cases is reported in figure (6). From the graph, it is observed that a good impedance matching is obtained. From the results, it is evident that experimental and simulated values are in good agreement with each other. The resonant frequency in both the cases also shows a good agreement. The simulation and experimental results show that the proposed antenna can be used as a dual band antenna.

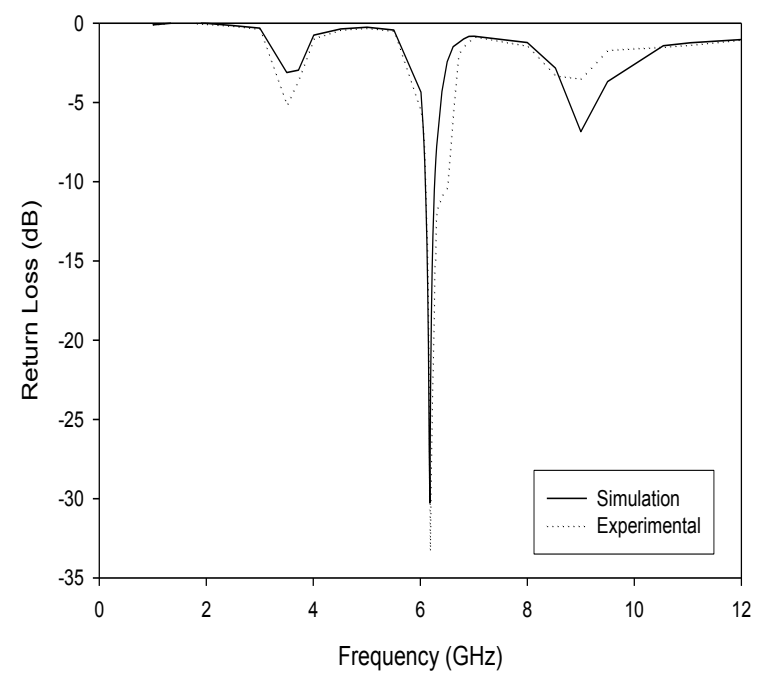

Figure 3. Simulation and Experimental variation of Return loss with frequency (without defect).

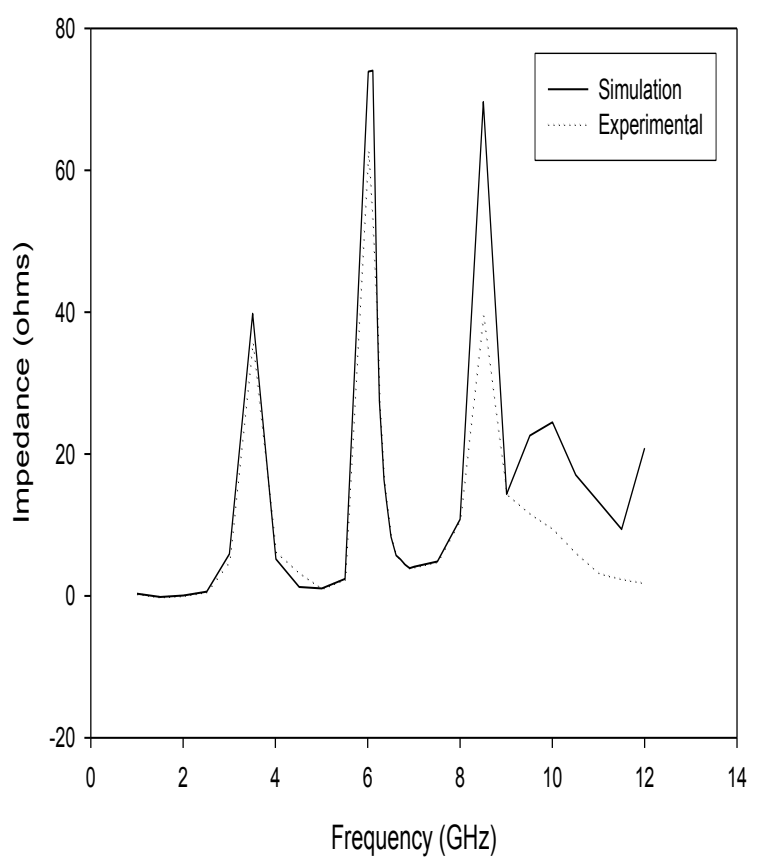

Figure 4. Simulation and Experimental variation of Impedance with frequency (without defect).

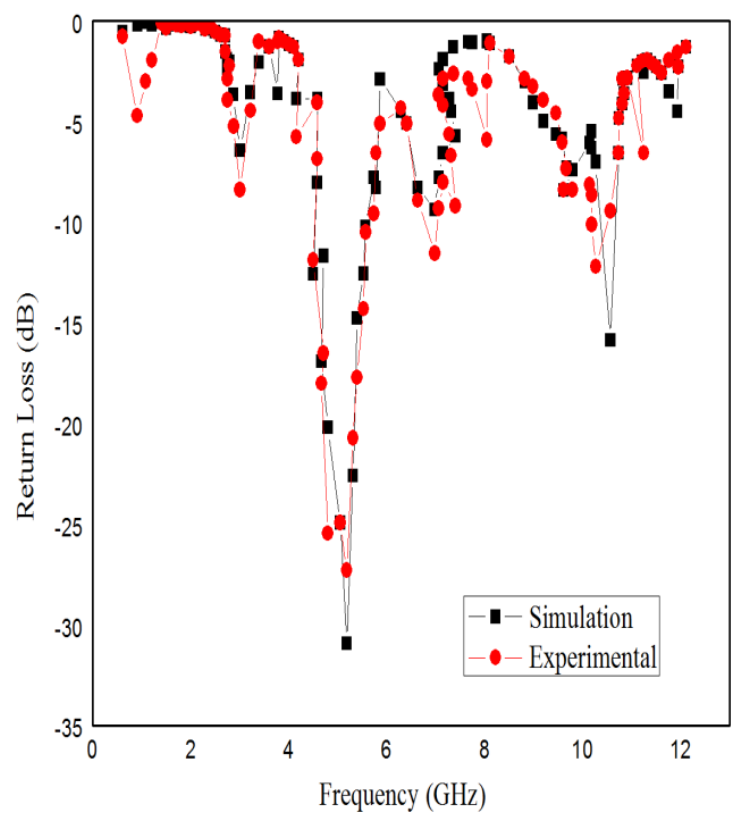

Figure 5. Simulation and Experimental variation of Return loss with frequency (with defect). 


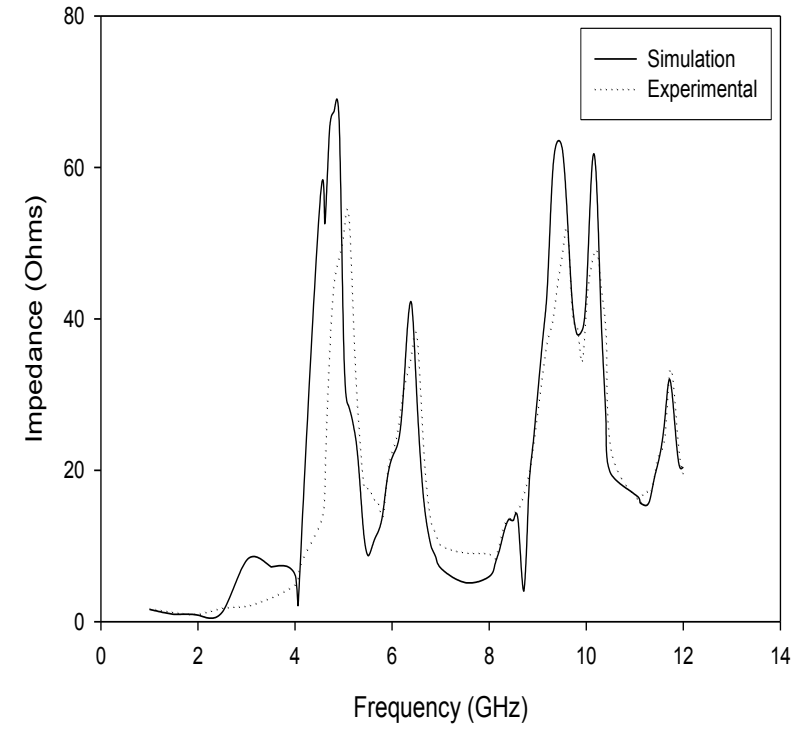

Figure 6. Simulation and Experimental variation of Impedance with frequency (with defect).

\subsection{Far field analysis}

The radiation patterns for both cases of the antenna are also measured within the frequency range are shown in figure (7) and figure (8). The polar plot of the radiation pattern is shown for $\mathrm{Phi}=0$ and $\mathrm{Phi}=$ 90 and between Theta/degree vs. $\mathrm{dBi}$ for both the cases.

Figure (7) shows the radiation pattern for the antenna without defect. In fig. 7 (a), for Phi $=0$ deg., at resonant frequency $6 \mathrm{GHz}$ and $3 \mathrm{~dB}$ angular width in the direction 27.0 deg., the side lobe level is $-2.3 \mathrm{~dB}$. In fig. 7 (b), for $\mathrm{Phi}=0 \mathrm{deg}$., at resonant frequency 8 $\mathrm{GHz}$ and $3 \mathrm{~dB}$ angular width in the direction 27.0 deg., the side lobe level is $-2.1 \mathrm{~dB}$. In fig. 7 (c), for $\mathrm{Phi}=90 \mathrm{deg}$., at frequency $8 \mathrm{GHz}$, the antenna gain is $2.8 \mathrm{dBi}$ in the main lobe direction $33.0 \mathrm{deg}$. For 3 $\mathrm{dB}$ angular width in the direction $85.7 \mathrm{deg}$., the side lobe level is about $-3.1 \mathrm{~dB}$. In fig. 7 (d), for $3 \mathrm{~dB}$ angular width, the side lobe level is $-2.8 \mathrm{~dB}$.

Figure (8) shows the radiation pattern for the antenna with defected ground plane. In fig. 8 (a), for Phi $=0$ deg., at center frequency $8 \mathrm{GHz}$, the antenna gain is $8.7 \mathrm{dBi}$ in the main lobe direction $34.0 \mathrm{deg}$. In fig. 8 (b) and 8(c), for Phi $=90$ deg., at resonant frequency $8 \mathrm{GHz}$, the antenna gain is $6.1 \mathrm{dBi}$ in the main lobe direction $149 \mathrm{deg}$. Within $3 \mathrm{~dB}$ angular width in the direction 28 deg., the side lobe level is about -10.8 $\mathrm{dB}$.

At resonant frequency $5 \mathrm{GHz}$, in fig. 8 (d), for Phi $=$ 90 deg., the directivity Abs plot shows the antenna gain of $5.6 \mathrm{dBi}$ in the main lobe direction $135.0 \mathrm{deg}$. Within $3 \mathrm{~dB}$ angular width in the direction $48.4 \mathrm{deg}$., the side lobe level is $-9.2 \mathrm{~dB}$. For directivity theta plot, in fig. 8 (e), the antenna gain is $5.5 \mathrm{dBi}$ in the main lobe direction $136 \mathrm{deg}$. Within $3 \mathrm{~dB}$ angular width in the direction 46.5 deg., the side lobe level is $-12.1 \mathrm{~dB}$.

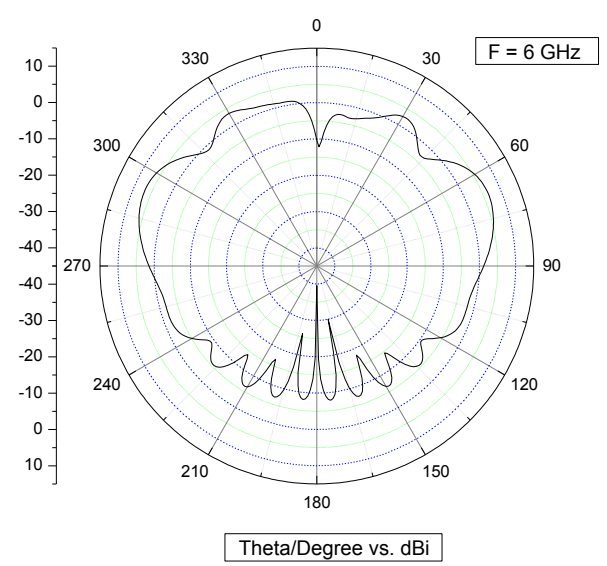

(a)

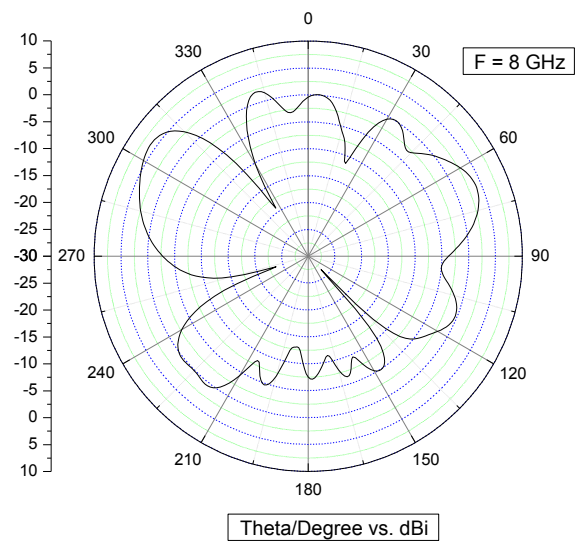

(b)

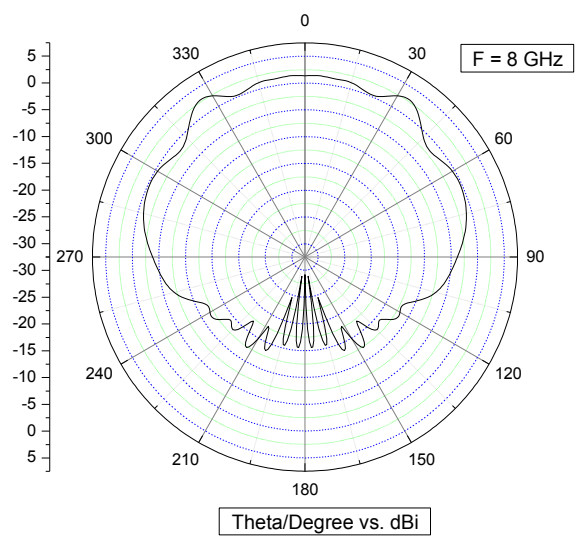

(c) 


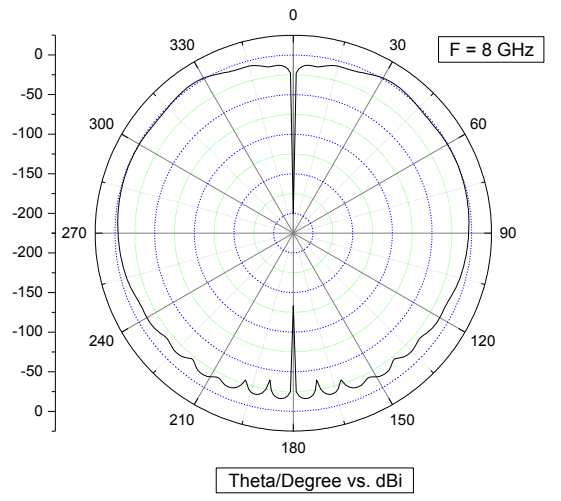

(d)

Figure 7. Radiation pattern (without defect) (a) Directivity Abs $(\mathrm{Phi}=0)$ Theta/Degree vs. dBi (6 $\mathrm{GHz})$

(b) Directivity Abs $(\mathrm{Phi}=0)$ Theta/Degree vs. dBi $(8$ $\mathrm{GHz})$

(c) Directivity Abs $(\mathrm{Phi}=90)$ Theta/Degree vs. $\mathrm{dBi}$ (8 GHz)

(d) Directivity Theta $(\mathrm{Phi}=90)$ Theta/Degree vs. $\mathrm{dBi}$ $(8 \mathrm{GHz})$

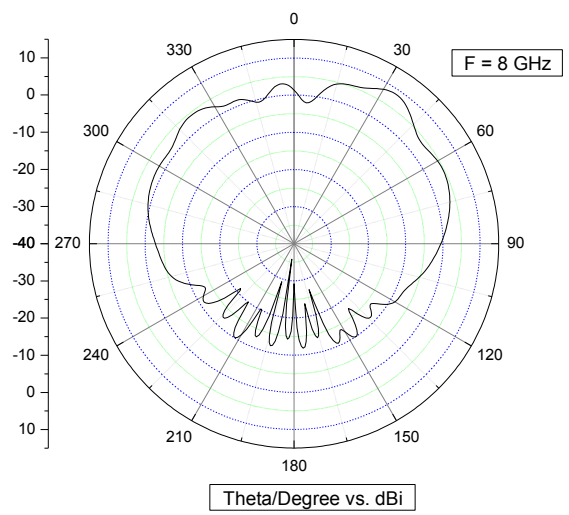

(a)

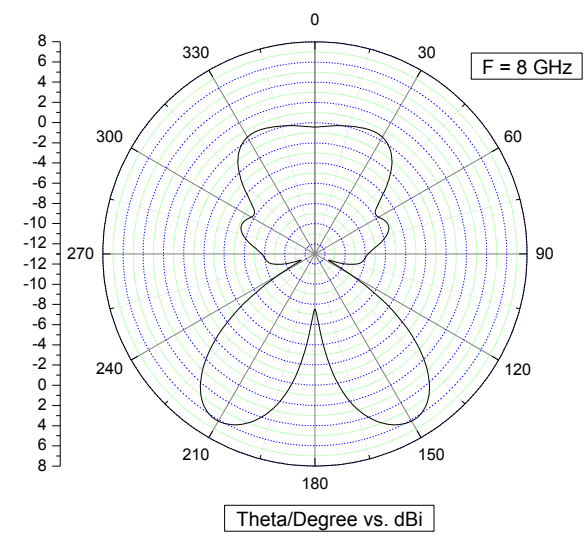

(b)

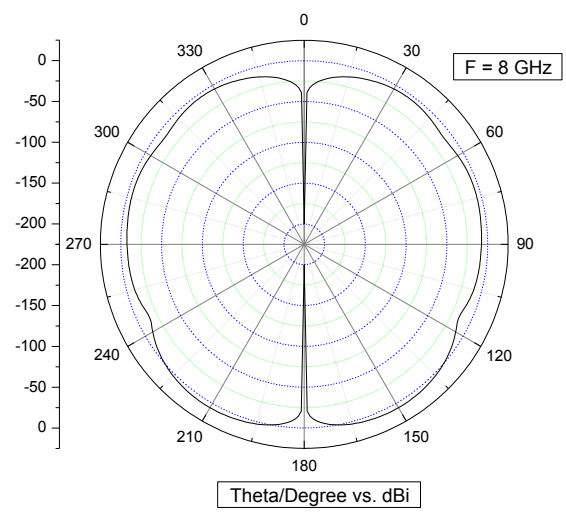

(c)

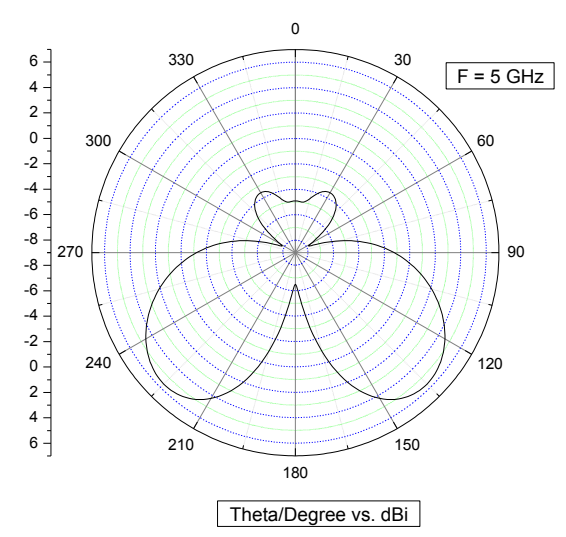

(d)

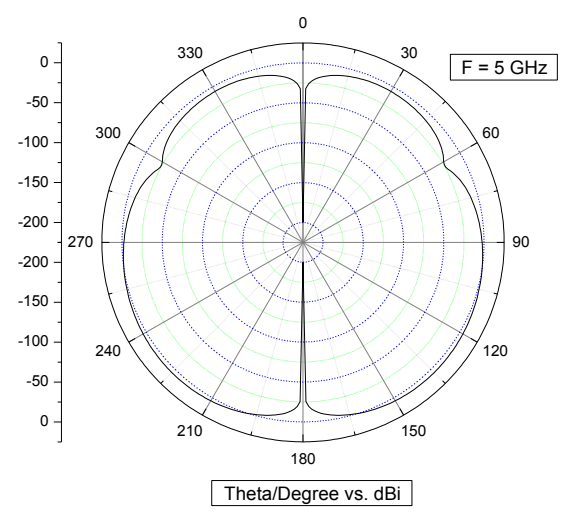

(e)

Figure 8. Radiation pattern (with defect)

(a) Directivity Abs $(\mathrm{Phi}=0)$ Theta/Degree vs. $\mathrm{dBi}(8$ $\mathrm{GHz}$ )

(b) Directivity Abs $(\mathrm{Phi}=90)$ Theta/Degree vs. dBi $(8 \mathrm{GHz})$

(c) Directivity Theta $(\mathrm{Phi}=90)$ Theta/Degree vs. $\mathrm{dBi}$ $(8 \mathrm{GHz})$ 
(d) Directivity Abs $(\mathrm{Phi}=90)$ Theta/Degree vs. dBi (5 GHz)

(e) Directivity Theta $(\mathrm{Phi}=90)$ Theta/Degree vs. $\mathrm{dBi}$ $(5 \mathrm{GHz})$

From the comparison of the results, it is shown that when the antenna ground is not defected the antenna gain is less and the side lobe level is also $-3.1 \mathrm{~dB}$. But when the defect in the ground plane is introduced, the gain of the antenna increases and almost doubles the value and thus the side lobe level also decreases to $10.8 \mathrm{~dB}$ for central resonant frequency $8 \mathrm{GHz}$. Also for resonant frequency $5 \mathrm{GHz}$, the antenna gain is increased and the corresponding side lobe level also decreases to a good extent of up to $-12.1 \mathrm{~dB}$. Therefore a significant reduction in the back radiation and thus the side lobe level is obtained with an increased gain.

This defected ground technique with gap coupling enhances the impedance bandwidth and the antenna gain thereby reducing the overall size of the antenna structure and is a convenient way to realize wideband microstrip antenna. By introducing defect in the antenna design structure, the impedance bandwidth increases up to approximately 3-4 times. Also the antenna gain enhances to almost double the value of the conventional antenna structure. The side lobe level which is an important parameter and must be as low as possible is also reduced to a good extent for better antenna transmission and radiation.

\section{Conclusion}

A novel coaxially fed dual band gap coupled multiple ring microstrip antenna with a defected ground has been presented. Dual frequency operation of the presented antenna makes it applicable in communication systems such as GPS and GSM and services of PCS and IMT-2000 as well. The antenna is simple to design and easy to fabricate. A significant increase in the peak antenna gain for their central resonant frequency is achieved. Experiments were carried out to verify the results predicted in the simulation. Good agreement between the measured and simulated data has been confirmed. In addition, the bandwidth, the antenna gain, and the side lobe level of the radiation pattern are all improved when the defected ground plane is introduced. The same technique presented in this communication can be applied to various different antenna designs for better results. This antenna design can be used as a multiband antenna in the high frequency applications and wireless communications.

\section{Acknowledgements}

Authors acknowledge the support provided both financially and instrumental by Electromagnetic Analysis Lab, JUIT, Solan, India.

\section{References}

1. Targonski, S.D., R.B. Waterhouse and D. M. Pozar, "Design of wideband aperture-stacked patch microstrip antennas", IEEE Trans. Antennas Propagat., vo1. 46, pp. 1245-1251, Sept. 1998.

2. Araki, K., H., Ueda, and M., Takahashi, "Numerical analysis of circular disk microstrip antenna with parasitic elements", IEEE Transactions on Antennas and Propagation 34(12), pp. 13901394, 1986.

3. Qu, D., Shafai, L., and Foroozesh, A. 'Improving microstrip patch antenna performance using EBG substrates', IEE Proc., Microw. Antennas Propag., 153, (6), pp. 558-563, 2006.

4. Zainud-Deen, S. H., M. E. Badr, E. El-Deen, K. H. Awadallaand H. A. Sharshar, "Microstrip antenna with defected ground plane structure as a sensor for landmines detection", Progress In Electromagnetics Research B, Vol. 4, pp. 27-39, 2008

5. Bao, X. L. and M. J. Ammann, "Dual-frequency circularly- polarized patch antenna with compact size and small frequency ratio," IEEE Trans. Antennas Propag., Vol. 55, No. 7, pp. 2104-2107, 2007.

6. Weng, L. H., Y.-C. Guo, X.-W. Shi, and X.-Q. Chen, "An overview on defected ground structure," Progress In Electromagnetics Research B, Vol. 7, pp. 173-189, 2008.

7. Lim, I.-S., C.-S. Kim, Y.-T. Lee, D. Ahn, and S. Nam, "Vertically periodic defected ground structure for planar transmission lines," Electronics Letters, Vol. 38, No. 75, pp. 803-804, July 2002.

8. Lim, J. S., C. S. Kim, Y. T. Lee, D. Ahn, and S. Nam, "A spiral-shaped defected ground structure for coplanar waveguide," IEEE Microwave Wireless Comp. Lett., Vol. 12, No. 9, pp. 330-332, 2002.

9. Guha, D., M. Biswas, and Y. M. M. Antar," Microstrip patch antenna with defected ground structure for Cross Polarization Suppression", IEEE Antennas and Wireless Propag. Lett., vol. 4, pp. 455458, 2005.

10. Kandwal, A and, S. K. Khah, "Improved characteristics of DGS ring antenna in L-Band," Antennas and Propagation Conference (LAPC), 2011 Loughborough IEEE Xplore, pp. 1-5, 2011.

11. Karmakar, N. C. and S. K. Padhi, "VSAT Broadband Shared Aperture Antennas" International Journal of RF und Microwave Computer-Aided Engineering, March 2003.

12. Sharma, R., A. Kandwal, S. K. Khah, "Compact Wideband Circular Ring Defected Ground Antenna", 
Advanced Computational Techniques in Electromagnetics, Volume 2012, Article ID acte00107, 5 Pages doi: 10.5899/2012/acte-00107, 2012.

13. Chayono, R., Y. Kimura, and M. Haneishi," An improved multiband performance using defected ground structure," IEICE Society Conf., B-1-106, Sept. 2007.

14. Guha, D., S. Biswas, M. Biswas, J. Y. Siddiqui, and Y. M. M. Antar, "Concentric ring-shaped defected ground structures for microstrip applications", IEEE Antennas and Wireless Propag. Lett., vol. 5, pp. 402-405, 2006.

15. Kandwal, A., T. Chakravarty and S. K. Khah, "Circuital Method for Admittance Calculation of Gap-Coupled Sectoral Antennas", Microwave and Optical Technology Letters, vol. 54, (1), pp. 210-213, 2012.

16. Chen, J., Z. B. Weng, Y. C. Jion, and F. S. Zhang, "Lowpass filter design of hilbert curve ring defected ground structure," Progress In Electromagnetics Research, PIER 70, pp. 269-280, 2007.

17. Hamad, E. K. I., A. M. E. Safwat, and A. S. Omar, "Controlled capacitance and inductance behaviour of L-shaped defected ground structure for coplanar waveguide," IEE Proc. - Microwave Antennas Propag., Vol. 152, No. 5, pp. 299-304, October 2005.

18. Joung, M.-S., J.-S. Park, and H.-S. Kim, “A novel modeling method for defected ground structure using adaptive frequency sampling and its application to microwave oscillator design," IEEE Transaction on Microwave Theory and Techniques, Vol. 41, No. 5, pp. 1656-1659, May 2005.

19. Horii, Y. and M. Tsutsumi, "Harmonic control by photonic band gap on microstrip patch antenna," IEEE Microwave and Guided Wave Letters, Vol. 9, pp. 13-14, January 1999.

20. Yang, H.-Y. D., N. G. Alexopoulos, and E. Yablonovitch, "Photonic bandgap materials for highgain printed circuit antennas," IEEE Trans. Antennas Propagat., Vol. 45, pp. 185-187, Jan. 1997.

21. Arya, K. Ashwini, M. v. Kartikeyan, A. Patnaik, "Efficiency Enhancement of Microstrip Patch Antenna with Defected Ground Structure," Proceedings of International Conference on Microwave, pp. 729-731, 2008.

22. Jan, J. Y. and K. L. Wong, "Single-feed dualfrequency circular microstrip antenna with an openring slot," Microw. Opt. Technol. Lett., vol. 22, no. 3, pp. 157-159, Aug. 1999.

23. Lu, J. H., "Dual-frequency operation of a singlefeed rectangular microstrip antenna with a pair of comb-shaped slots," Microw. Opt. Technol. Lett., vol. 23, pp. 183-186, Nov. 5, 1999.

24. Binoy, G. S., C. K. Anandam, P. Mohanan, K. Vasudevan, and K. G. Nair, "Single-feed dual- frequency dual-polarized slotted square microstrip antenna," Microw. Opt. technol. Lett., vol. 25, pp. 395-397, June 20, 2000. 